$\check{I-ト}$

\title{
玄米中の殺菌剤テクロフタラム及びその代謝物 テクロフタラムイミドの分析
}

(平成 9 年 9 月 16 日受理)

$\begin{array}{ll}\text { 津村ゆかり* } & \text { 中村優美子* } \\ \text { 外海 泰 秀* } & \text { 柴 田 正* }\end{array}$

\section{Determination of the Fungicide Tecloftalam and Its Metabolite Tecloftalam-imide in Brown Rice}

\author{
Yukari Tsumura, Yumiko Nakamura, Yasuhide Tonogai \\ and Tadashi Shibata \\ (National Institute of Health Sciences, Osaka Branch: 1-1-43, Hoenzaka, \\ Chuo-ku, Osaka 540-0006, Japan)
}

The fungicide tecloftalam and its metabolite tecloftalam-imide were individually determined. They were extracted from brown rice with acetone and re-extracted with ethyl acetate. The extract was partitioned between $n$-hexane and acetonitrile to remove oil, and then charged on a Sep-Pak Plus Florisil cartridge. Tecloftalam-imide was eluted with $50 \%$ diethyl ether$n$-hexane and then tecloftalam was eluted with methanol. Tecloftalam-imide was determined on a gas chromatograph (GC) equipped with a capillary column DB-1 and an electron capture detector (ECD). Tecloftalam was converted into tecloftalam-imide by addition of acetic anhydride, and determined by GC-ECD. Recoveries of tecloftalam and tecloftalam-imide from rice spiked at levels of $0.2 \mathrm{ppm}$ were $89.3 \pm 1.9 \%$ and $82.6 \pm 1.5 \%$, respectively. Detection limits were $0.01 \mathrm{ppm}$ in samples.

(Received September 16, 1997)

Key words: テクロフタラム tecloftalam; 代謝物 metabolite; テクロフタラムイミド tecloftalamimide; ガスクロマトグラフィー (ECD) GC-ECD; 農薬 pesticide; 米 rice

緒言

イネ白葉枯病殺菌剤テクロフタラム ${ }^{1)}($ Fig.1)の分析法 を検討した。

白葉枯病は Xanthomonas campestris pv. oryzae に よって引き起こされるイネの最む重大な細菌病であ る $^{2), 3)}$. テクロフタラムはこの病変に対する殺菌剤とし て開発され，1979 年に韓国で実用化され，我が国にお いても昭和 62 年に登録された. 平成 8 年 9 月 2 日，厚 生省より食品中の残留基準值と分析法が告示された ${ }^{4}$.

水田に散布されたテクロフタラムは, 土壌中ではテト ラクロロフタル酸部分において塩素原子の脱離が，イネ

* 国立医薬品食品衛生研究所大阪支所：干540-0006 大阪市 中央区法円坂 1-1-43
植物体上ではイミド化が主に進行する5). したがって， 玄米中のテクロフタラムは親化合物及びテクロフタラム イミド（Fig. 1, 以下ィミド体という）の混合物として<smiles>O=C(O)c1c(Cl)c(Cl)c(Cl)c(Cl)c1C(=O)Nc1cccc(Cl)c1Cl</smiles>

Tecloftalam<smiles>O=C1c2c(Cl)c(Cl)c(Cl)c(Cl)c2C(=O)N1c1cccc(Cl)c1Cl</smiles>

Tecloftalam-imide
Fig. 1. Chemical structures of tecloftalam and tecloftalam-imide 
残留する. 厚生省の残留基準値はテクロフタラムとイミ ド体の合量として定められている.

ラットへの経口投与実験では, イミド体はほとんど未 変化で糞中に排泄されるのに対し，テクロフタラムは 4 〜6 割程度吸収される ${ }^{6}$. また急性毒性, 変異原性とも イミド体よりテクロフタラムで高い1). このようにテク ロフタラムとイミド体は毒性学的な性質が異なるため, 正確な生体影響の評価のためには両者を分別して定量す る必要がある.

テクロフタラムはカルボキシル基を有するため, その ままの形では GC による検出が困難である. 分子内で脱 水縮合反応を行い，イミド体に変換することで分析が容 易になる．具体的な分析例としては，厚生省の告示法の 他に，イネ葉溢液 ${ }^{7)}$ を試料とした報告及び農薬登録保留 基準 ${ }^{8)}$ の方法がある.これらはいずれあテクロフタラム とイミド体を分離せずに反応させて分析する方法であ り，両者を分別定量することはできない.

著者らはテクロフタラムとイミド体をフロリジルミニ カラムを用いて分別定量する試験法を作成した。 その 際, イミド体がガスクロマトグラフのガラスインサート に吸着する現象を見いだし，対処法を示した.

なお，テクロフタラムはイネにのみ使用され，残留基 準も米にのみ設定されているため，分析法検討の試料に は米を用いた.

\section{実験方法}

\section{1. 標 準 品}

テクロフタラム（和光純薬工業(株)製）純度 $99.9 \%$, 約 $25 \mathrm{mg}$ を正確に量り採り，20\%メタノール/アセ卜 ンで溶解して $50 \mathrm{~mL}$ とした.

テクロフタラムイミド（和光純薬工業(株)製）純度 99.7\%, 約 $25 \mathrm{mg}$ を正確に量り採り, アセトンで溶解 して $50 \mathrm{~mL}$ とした.

\section{2. 試料}

玄米は大阪市内の小売店で購入した.

\section{3. 装}

\section{置}

ガスクロマトグラフ：島津 GC-17A（電子捕獲型検出 器付き), $\mathrm{AOC}-17$ (オートインジェクター), C-R $4 \mathrm{~A}$ (デー夕処理装置)

ガスクロマトグラフー質量分析計：日本電子 JMS-DX 302 (質量分析計), MS GCG 06 (ガスクロマトグラ フ), JMA-DA5000（データ処理装置）

\section{4. 試薬}

Sep-Pak Plus Florisil: Millipore 社製

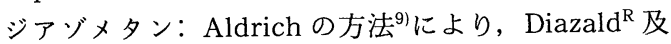
びミニジアザルドキットを用いて合成.

\section{5. 試験溶液の調製}

試験液の調製方法を Scheme 1 に示した.

\section{6. 測定条件}

\subsection{GC-ECD 条件}

カラム: DB-1 (内径 $0.25 \mathrm{~mm}$, 長さ $30 \mathrm{~m}$, 膜厚 $0.25 \mu \mathrm{m}, \mathrm{J} \& \mathrm{~W}$ 社)；力ラム温度： $60^{\circ} \mathrm{C}$ で 2 分間保持 し, その後毎分 $20^{\circ} \mathrm{C}$ で昇温し, $250^{\circ} \mathrm{C}$ に到達後 34 分間 保持する; 注入口温度： $250^{\circ} \mathrm{C}$; 注入方式 スプリット レス; 検出器温度: $300^{\circ} \mathrm{C}$; キャリヤーガス: リウム $1 \mathrm{~kg} / \mathrm{cm}^{2}$; シラン処理インサート：レステック社製ス プリットレス用; 注入量： $1 \mu \mathrm{L}$

\section{$6.2 \mathrm{GC} / \mathrm{MS}$ 条件}

カラム温度： $60^{\circ} \mathrm{C}$ で 2 分間保持し, その後毎分 $16^{\circ} \mathrm{C}$ で昇温し, $250^{\circ} \mathrm{C}$ に到達後 34 分間保持する; イオン化 電圧： $70 \mathrm{eV}$ ；イオン化法：電子衝撃 $(\mathrm{EI})$ 法；イオン化 電流： $300 \mu \mathrm{A}$ ；イオン源温度： $250^{\circ} \mathrm{C}$ ， スキャン範囲： $m / z 50 \sim 500 ;$ スキャンスピード： $1 \mathrm{scan} / \mathrm{sec；その}$ 他の条件は GC-ECD に同じ.

\section{7. 検 量 線}

テクロフタラム：テクロフタラム標準溶液を酢酸エチ ルで希釈して $0.02 \sim 0.8 \mu \mathrm{g} / \mathrm{mL}$ の溶液を調製し, 試料

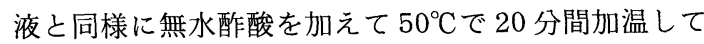
イミド化した後 $n$-ヘキサンで抽出し, 検量線用標準液 とした。

イミド体：イミド体標準溶液を $n$-ヘキサンで希釈し て $0.02 \sim 0.8 \mu \mathrm{g} / \mathrm{mL}$ とし, 検量線用標準液とした.

\section{8. 添加回収実験}

蒸留水で膨潤させた試料 $10.0 \mathrm{~g}$ に，テクロフタラム 又はイミド体標準液（各 $2 \mu \mathrm{g} / \mathrm{mL}$, アセトン) $1 \mathrm{~mL}$ を, 抽出開始の 1 時間前に添加した（各 $0.2 \mathrm{ppm}$ 添 加).

\section{結果及び考察}

\section{GC 用カラムの選択}

既報7, 8), 10),11)のイミド体分析例においては，いずれも 無極性力ラムが採用されている.そこでまず DB-1（内 径 $0.25 \mathrm{~mm}$ ）による分離を試みたところ，イミド体は 保持時間約 37 分, $0.02 \mathrm{ng}$ の検出限界 (S/N > 3) で良 好に定量できた. しかし若干テーリングが見られたた め, 同じ内径の DB-5 で分析したところ, ピーク形状は やや改善したが保持時間が長かった (約 57 分). DB17 では良好なピーク形状が得られたが, 更に保持時間 が長く実用的でなかった (約 69 分). DB-17 (内径 $0.53 \mathrm{~mm}$ ) を使用した場合, 保持時間は短かかった (約 36 分) がピーク形状はブロードであった. そこで カラムとしては DB-1（内径 $0.25 \mathrm{~mm}$ ）を用いることと した.

\section{2. テクロフタラムのメチル化}

テクロフタラムを GC で測定するための簡便な誘導体 化法としては, メチル化とイミド化が考えられる.イミ ド化では分析対象の代謝物之同じ化合物に変換されるた め, メチル化がより望ましい，そこでテクロフタラムの 
Rice $10 \mathrm{~g}(420 \mu \mathrm{m})$

$-\mathrm{H}_{2} \mathrm{O} 20 \mathrm{~mL}$

stand for 2 hours

-acetone $100+50 \mathrm{~mL}$

homogenize ( $3 \mathrm{~min})$

filter with filter paper (No. 5A)

Filtrate

evaporate $(30 \mathrm{~mL})$

$-10 \% \mathrm{NaCl}$ soln. $100 \mathrm{~mL}$

-ethyl acetate $100+50 \mathrm{~mL}$

shake (5 min)

\begin{tabular}{l} 
Org. layer \\
\hline dehydrate with $\mathrm{Na}_{2} \mathrm{SO}_{4}$ \\
filter \\
evaporate to dryness \\
$-n$-hexane $30 \mathrm{~mL}$ \\
$-\mathrm{CH}_{3} \mathrm{CN}($ saturated with $n$-hexane) $30 \mathrm{~mL} \times 3$ \\
shake (5 min)
\end{tabular}

(2) $50 \%$ diethyl ether- $n$-hexane $10 \mathrm{~mL} \rightarrow$ evaporate $(5 \mathrm{~mL}) \rightarrow$ GC-ECD

(3)acetone $10 \mathrm{~mL}$ (discard)

(4)methanol $20 \mathrm{~mL}$

evaporate to dryness

-ethyl acetate $1 \mathrm{~mL}$

- acetic anhydride $1 \mathrm{~mL}$

$50^{\circ} \mathrm{C}, 20 \mathrm{~min}$

$-10 \% \mathrm{NaCl}$ soln. $50 \mathrm{~mL}$

$n$-hexane $50 \mathrm{~mL}$

shake (5 min)

$\begin{array}{lc}\text { Org. layer } & \text { Aq. layer } \\ \text { dehydrate with } \mathrm{Na}_{2} \mathrm{SO}_{4} & \text { discard } \\ \text { evaporate }(5 \mathrm{~mL}) \rightarrow \mathrm{GC}-\mathrm{ECD} & \end{array}$

Scheme 1. Analytical procedure for tecloftalam and tecloftalam-imide in rice

* Conditioned with $n$-hexane $(10 \mathrm{~mL})$. Tecloftalam-imide was eluted in fraction (2), and tecloftalam, in fraction (4). 
標準液をジアゾメタンでメチル化して GC 分析を試みた が, 単一の生成物は得られなかった。メチル化後の試験 液のガスクロマトグラムには 3 本のピークが出現し, その 1 つはマススペクトル・保持時間共イミド体標準 品之一致した．別の 1 つはマススペクトルからメチル 化生成物である methyl 3,4,5,6-tetrachloro- $N$-(2,3 dichlorophenyl)- $N$-methyl phthalamate と推定され た. 残る 1 つのピークは, 可能な生成物 methyl 3,4,5,6 tetrachloro- $N$-(2,3-dichlorophenyl) phthalamate から 推定されるマスパターンを示さず，構造不明であった。

テクロフタラムはカルボキシル基周辺に立体障害があ るため, メチル基が導入されにくく複数の生成物が生じ ると考えられる，そこでメチル化は断念し，ミニカラム でテクロフタラムをイミド体と分離した後イミド化反応 を行い，定量することとした。

\section{3. イミド化反応条件の検討}

テクロフタラムのイミド化反応に要する時間を検討し た. Fig. 2 に示したとおり，約 20 分の反応時間でイミ ド体生成量は最大（約 92\%）になり，その後やや減少 した。 そこで反応時間は 20 分とした. 反応の回収率が 100\%でないことから，テクロフタラムの定量の標準溶 液としてはイミド体溶液でなくテクロフタラムを同条件

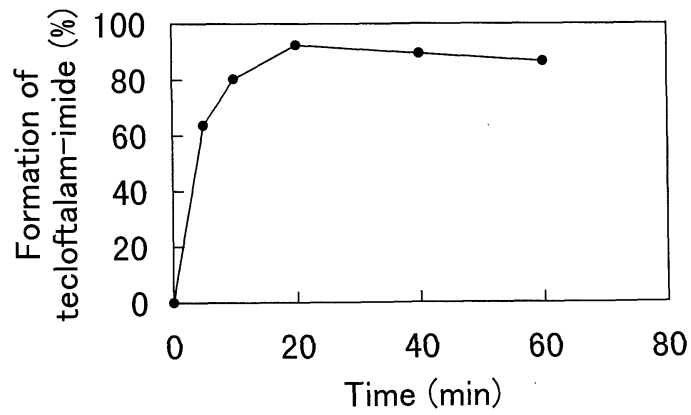

Fig. 2. Time course for formation of tecloftalam-imide from tecloftalam
でイミド化したあのが適当と考えられた。 なお，生成し たイミド体は GC/MS で確認した。

\section{4. 分離・精製法の検討}

テクロフタラムとイミド体をフロリジルミニカラム (Sep-Pak Plus Florisil) で分離する方法を検討した. イ ミド体は $50 \%$ ジェルエーテルーn-ヘキサンで溶出する のが最適であった. テクロフタラムはアセトンでは全く 溶出されず，メタノールで溶出された. Table 1 に最終 的に決定した溶出条件と回収率を示した. 最初に $n$-へ キサンで洗浄し，続いて 50\%ジェチルエーテルーn-へキ サンでイミド体を溶出し，アセトンで洗浄し，メタノー ルでテクロフタラムを溶出することとした．この方法に よって，テクロフタラムとイミド体は相互に混入するこ となく完全に分離できた.

\section{5. ピーク面積の変動}

前項の条件で玄米抽出液を分画し， GCにより分析し たところ，イミド体標準液のピーク面積の変動が非常に 大きかった。 ガラスインサートの交換後に感度が低下 し, 抽出液の注入後に感度が高くなる傾向があった. 試 みに，イミド体と同じ塩素原子数のへキサクロロベンゼ ンを単独又は試験液と混合して注入したが，ピーク面積 の変動はほとんど見られなかった．したがって，イミド 体のピーク面積変動は, 検出器が原因ではなく, イン サートに吸着する等イミド体固有の問題と考えられた. カラムの交換後も感度低下は起こったが，インサートの 影響の方が大きかった。

イミド体を玄米抽出液に添加したあのと, 同一濃度の ヘキサン溶液とを交互に注入してピーク面積比の推移を 調べたところ，シラン処理したガラスインサートを用い て玄米抽出液を数回〜20 回程度繰り返し注入した後に は 0.96〜1.04の比が得られ, 定量に用いることができ た. 未処理のインサートでは繰り返し注入の後もピーク 面積比は 1.5 程度であった. したがって感度変化への対 応としては

1. シラン処理したガラスインサートを使用する.

2. 最初の測定時には, 玄米の抽出液を繰り返し注入

Table 1. Recoveries of Tecloftalam and Tecloftalam-imide from Sep-Pak Plus Florisil

\begin{tabular}{lccc}
\hline \hline \multirow{2}{*}{ No. Eluting solvent } & \multirow{2}{*}{$\begin{array}{c}\text { Volume } \\
(\mathrm{mL})\end{array}$} & \multicolumn{2}{c}{ Recovery (\%) } \\
\cline { 3 - 4 } & & Tecloftalam & Tecloftalam-imide \\
\hline (1) $n$-Hexane & 10 & 0 & 0 \\
(2) 50\% Diethyl ether-n-hexane & 10 & 0 & 95.3 \\
(3) Acetone & 10 & 0 & 0 \\
(4) Methanol & 10 & 85.3 & 0 \\
(5) Methanol & 10 & 2.3 & 0 \\
(6) Methanol & 0 & 0 \\
\hline
\end{tabular}

Tecloftalam $(2 \mu \mathrm{g})$ or tecloftalam-imide $(2 \mu \mathrm{g})$ in hexane was charged on Sep-Pak Plus Florisil cartridge and eluted with solvents (1) (6) continuously. 


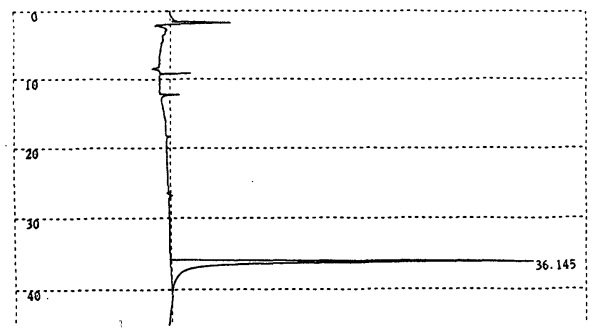

Tecloftalam-imide standard $(0.4 \mu \mathrm{g} / \mathrm{mL})$

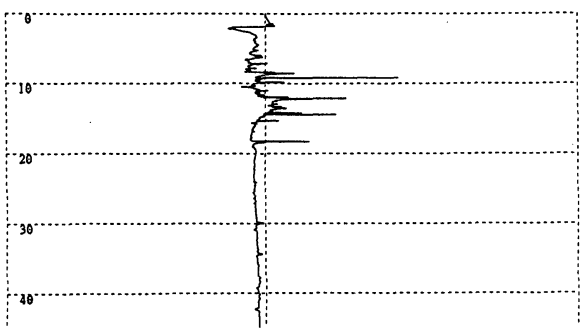

Rice extract, fraction (2)

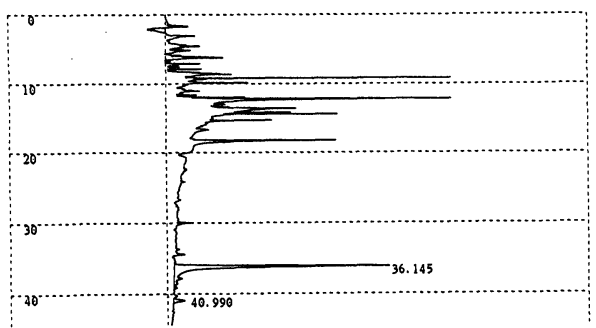

Fortified rice extract, fraction (2) $0.2 \mathrm{ppm}$ tecloftalam-imide was added.

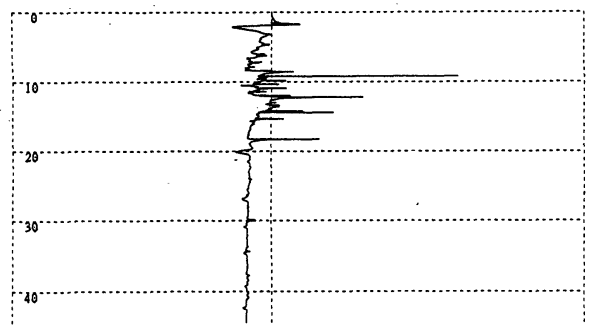

Fortified rice extract, fraction (2) $0.2 \mathrm{ppm}$ tecloftalam was added.

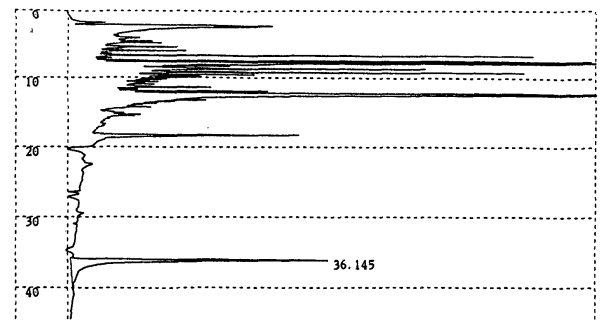

Tecloftalam standard after reaction $(0.4 \mu \mathrm{g} / \mathrm{mL}$ )

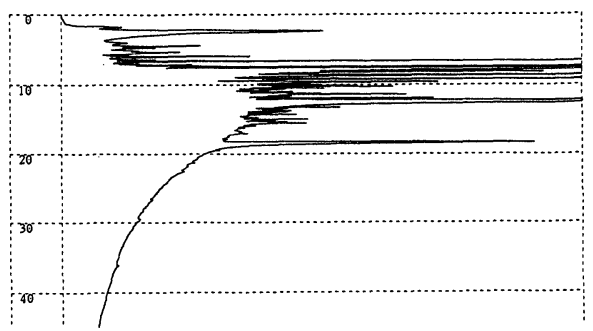

Rice extract, fraction (4)

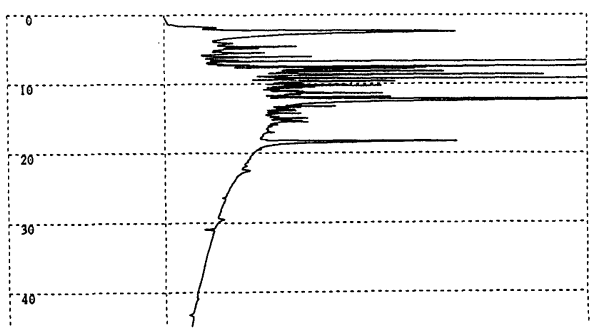

Fortified rice extract, fraction (4) $0.2 \mathrm{ppm}$ tecloftalam-imide was added.

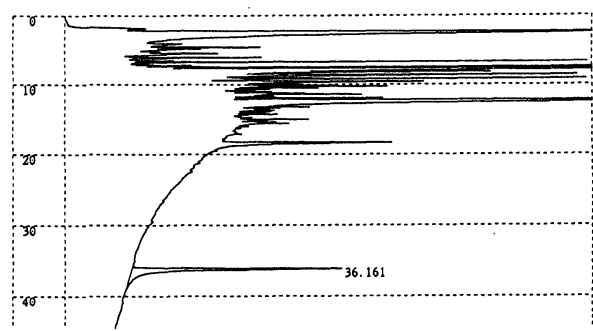

Fortified rice extract, fraction (4) $0.2 \mathrm{ppm}$ tecloftalam was added.

Fig. 3. Gas chromatograms of tecloftalam-imide standard and rice extract fraction (2): $50 \%$ diethyl ether- $n$-hexane; fraction (4): methanol GC conditions: column: DB-1 $(0.25 \mathrm{~mm}$ i.d. $\times 30 \mathrm{~m}, 0.25 \mu \mathrm{m}$ film thickness); oven temp.: $60^{\circ} \mathrm{C} \quad(2 \mathrm{~min}) \rightarrow\left(20^{\circ} \mathrm{C} / \mathrm{min}\right) \rightarrow 250^{\circ} \mathrm{C} \quad(34 \mathrm{~min})$; injection temp.: $250^{\circ} \mathrm{C}$; detector temp.: $300^{\circ} \mathrm{C}$; injection mode: splitless 
してインサートを不活性化する. 抽出液中のイミド体と ヘキサン中のイミド体のピーク面積比が 1 に近くなっ たことを確認してから本測定を行う。

3. ガラスインサートの交換直後，及び GC を数日間 以上停止した後に測定するときにも，2 の確認を行う.

この 3 点が有効であった.

また，テクロフタラム及びイミド体を含まないことを 確認した試料抽出液を用意すれば，標準添加法も可能で ある.

\section{6. 添加回収実験}

1〜5の検討結果に基づき，Scheme 1 に示した分析 法を設定した。この試験法によって調製した試験液のク ロマトグラムを Fig. 3 に示した. イミド体は第二画分 についても第四画分についても妨害なく検出できた.

玄米にテクロフタラム又はイミド体を $0.2 \mathrm{ppm}$ 添加 して，添加回収実験を行ったところ，それぞれ $89.3 \pm$ 1.9\%(3 試行)，82.6土1.5\%（3 試行）と回収率・再現 性とあ良好であった．本法の検出限界は試料中 0.01 $\mathrm{ppm}$ であった. テクロフタラムとイミド体の分析操作 中の相互変換は認められなかった.

\section{謝辞}

本研究を遂行するに当たり有益な御助言を頂いた大阪 府公害監視センター奥村為男先生に深謝いたします.
文献

1) Takahi, Y.: Jpn. Pestic. Inf. 46, 25 30 (1985).

2) 中神和人, 本田建夫：農楽誌. 6, 377 385 (1981).

3) Nakagami, K., Tanaka, H.: J. Pesticide Sci. 5, 511 516 (1980).

4) 厚生省告示：“食品, 添加物等の規格基準の一部を改正す る件”平成 8 年 9 月 2 日, 厚生第 221 号 (1996).

5) Kirkpatrick, D., Biggs, S. R., Conway, B., Finn, C. M., Hawkins, D. R., Honda, T., Ishida, M., Powell, G. P.: J. Agric. Food Chem. 29, 1,149 1,153 (1981).

6) Kirkpatrick, D., Finn, C. M., Conway, B., Hawkins, D. R., Honda, T., Ishida, M., Powell, G. P.: ibid. 29, 608 614 (1981)

7) Nakagami, K., Tanaka, H., Yamaoka, K., Tsujino, Y.: J. Pesticide Sci. 5, 607 609 (1980).

8）農薬環境保全対策研究会編：“農薬登録保留基準 残留農 薬基準ハンドブック一作物・水質残留の分析法—” 490 492 (1995) 化学工業日報社.

9) Aldrich 社編: Technical Information Bulletin, AL180 (1990)

10) 後藤真康, 加藤誠哉: “増補残留農薬分析法” p. 151 152 (1987) ソフトサイエンス社.

11) 農薬残留分析研究班編集：“最新農薬の残留分析法”, p. 595 596 (1995) 中央法規出版. 